\title{
DOS APORTES DEL LATÍN AL ESPAÑOL: EL VERBO DERIVAR Y LOS SUFIJOS EN - ARIA
}

\author{
Two contributions from latin to spanish: the verb derivar and suffix -aria
}

\section{Henry Campos Vargas*}

\section{RESUMEN}

Este artículo muestra cómo el verbo derivar ha sufrido cambios semejantes en el latín y en el español moderno. Además, rastrea los orígenes del sufijo - aria hasta la literatura romana arcaica.

Palabras clave: derivar, Plauto, verbo transitivo latino, verbo intransitivo, Aulularia.

\begin{abstract}
This paper shows how the verb derivar suffered similar changes in Latin language than in modern Spanish. Also it tracks origins of suffix -aria in the ancient Roman literature.

Key Words: derivate, Plautus, transitive Latin verb, intransitive verb, Aulularia.
\end{abstract}




\section{Del verbo derivar}

La vigésima primera edición del Diccionario de la Real Academia de la Lengua Española registra para la entrada derivar la siguiente información:

derivar. (Del lat. derivāre.) intr. Traer su origen una cosa de otra. Ú. t. c. prnl. \| 2. Mar. abatir, desviarse el buque de su rumbo. \|3. tr. Encaminar, conducir una cosa de una parte a otra. \|4. Gram. Traer una palabra de cierta raíz (1992: 685).

Salta a la vista la ausencia del sentido matemático de esta voz, a saber, obtener la derivada de una ecuación. Esta acepción se usó durante muchos años por estudiantes y profesores de los cursos de Cálculo diferencial e integral en expresiones como derivemos esta ecuación. Con esta acepción, se constituyó como sinónimo de diferenciar, voz que significa en su cuarta acepción

Mat. Calcular la diferencial de una cantidad variable (1992: 748).

Los libros de texto se cuidaron por largo tiempo de no emplear este uso para derivar, aunque sí recurrían a expresiones como al derivar tal ecuación, etc., que de alguna manera lo presuponen.

Sin embargo, en ese entonces la Real Academia sí registraba como lema derivada:

derivada. f. Mat. En las funciones matemáticas respecto a una variable, límite hacia el que tiende el cociente entre el incremente que resulta para la función y el atribuido a la variable, cuando este último tiende a cero. Si esta derivada se deriva con relación a la misma variable, se obtiene la derivada segunda y sucesivamente la tercera, etc. (1992: 685).

Aquí podría encontrarse el origen de este cambio semántico, ya que, aunque se trata de un sustantivo, tiene forma pasiva, lo que podría establecer una asociación hipotética con un supuesto verbo derivar en sentido matemático. En este sentido, derivar consistiría en un procedimiento de esta índole, descubierto de manera independiente por Newton y Leibniz, que puede ilustrarse con estos dos ejemplos: si $\mathrm{f}(\mathrm{x})=2$, entonces $\mathrm{f}^{\prime}(\mathrm{x})=0$, lo cual significa que cuando una ecuación es una constancia, su derivada (que se representa $\mathrm{f}^{\prime}(\mathrm{x})$ es 0 ). En cambio, si $\mathrm{f}(\mathrm{x})=\mathrm{x} 2$, entonces $\mathrm{f}^{\prime}(\mathrm{x})=2 \mathrm{x}$.

Al igual que su sinónimo diferenciar, derivar sería un verbo transitivo.

Ahora bien, en su vigésima segunda edición, el Diccionario de la Real Academia de la Lengua Española aceptó esta entrada:

derivar. (Del lat. derivāre.) intr. Dicho de una cosa: Traer su origen de otra. U. t. c. prnl. \| 2. Gram. Dicho de una palabra: Proceder de cierta raíz o de alguna otra palabra. U. t. c. tr. y c. pronl. Algunos derivan adrede de ad directum, pero otros no. $\| \mathbf{3}$. Mar. Dicho de un buque: abatir (\| desviarse de su rumbo). $\|$ 4. tr. Encaminar, conducir algo de una parte a otra. || 5. Mat. Obtener la derivada de una función (2001: 752).

Salta a la vista el empleo de este término en matemáticas y en la gramática. Su historia, en este último campo, fue semejante al explicado para el primero.

Desde el punto de vista de la lengua derivar es un verbo con doble régimen, transitivo e intransitivo, el cual contrasta sobremanera, tanto en este aspecto como en su semántica, con su precedente latino. Santiago Segura Munguía nos indica al respecto:

dērīvō, -āre, -āvī, -ātum [de, rīvus], tr. desviar, derivar [las aguas]: ex flumine, de un río; d. humorem extra segetes, desviar el agua fuera de los sembrados || [fig.] desviar: aliquid in domum suam, desviar algo hacia su casa, en provecho propio; $d$. culpam in aliquo, echar la culpa a alguno \| [Gram.] derivar [una palabra].

La semántica original procede de una acción concreta de carácter físico: desviar algo, en particular el agua. Este sentido originario es ejemplificado en la siguiente cita del Truculentus de Plauto, que corresponde a un monólogo de Cíamo, esclavo de Diniarco, al llevarle unos presentes a Fronesia, la hermosa cortesana:

nam iam de hoc obsonio de mina deminui una modo quinque nummos: mihi detraxi partem Herculaneam.

nam hoc adsimile est quasi de fluvio qui aquam derivat sibi: 
nisi derivetur, tamen omnis ea aqua abeat in mare;

nam hoc in mare abit misereque perit sine bona omni gratia. 565

haec cum video fieri, suffuror suppilo,

de praeda praedam capio.

meretricem ego item esse reor, mare ut est:

quod des devorat $<$ nec dat $>$ is umquam abundat (561-569).

Pues ya disminuí de la mina para las provisiones tan solo

cinco monedas: separé para mí la parte de Hércules.

Es como cuando alguien desvía agua de un río para sí:

si no se desviara, toda esa agua iría al mar;

Pues esto va a un mar y se pierde inútilmente sin ni un solo "gracias".

Cuando veo que esto pasa, hurto y

tomo la presa de una depredadora.

Yo creo que una meretriz es como el mar:

lo que le des, lo devora, y nunca da nada aunque esté en la abundancia.

Tal sentido evolucionó a un sentido figurado en derecho, echar la culpa a alguien, y a la gramática, en la que se aprovechó para expresar el fenómeno de formación de palabras. Este último cambio, de acuerdo con Charlton T. Lewis, habría tenido lugar después de la época de Augusto para sustituir la voz dīcō, empleada con este propósito (1879: 554). Al respecto, Segura Munguía ejemplifica esta particularidad con nomen $d . .$. , entendida como toma su nombre de... (2003: 237).

Cicerón recurre a esta acepción en De finibus bonorum malorumque:

quid autem est amare, e quo nomen ductum amicitiae est, nisi velle bonis aliquem affici quam maximis, etiamsi ad se ex iis nihil redundet?

¿Pero qué es amar, de la cual se deriva la palabra amistad, sino querer que el mayor de los bienes se prodigue a alguien en particular, aunque nada redunde en beneficio propio? (2012, II, 78).

La sintaxis ducti e vocabulo (ser derivada de una palabra) es sumamente próxima a la inteligencia contemporánea. Sin embargo, al asumir este papel la voz derivare enfrentó ciertos problemas, ya que en este campo semántico se aprecian algunas irregularidades iniciales en su empleo.

Su uso en gramática fue muy extendido. De acuerdo con el Oxford Latin Dictionary significa:

3 (gram.) To form (derivatives).

ata (nomina), ut a "uelocitate".. "uelox", et composita QUINT. Inst. I.6.38; nostri..in ando paulum..ausi 8.3.31; 8.3.36.

En este sentido, Lewis es coincidente al señalar:

B. Esp. in gramm., to derive, sc. one word from another (1879: 554).

Sin embargo, al consultar las fuentes clásicas se aprecia que la noción inicial que los romanos tuvieron de derivar difería considerablemente de la moderna. Quintiliano:

Considérese la siguiente cita de

XXXVIII. Sed hoc tanti fuit vertere, ut "merula", quia sola volat, quasi mera volans nominaretur. Quidam non dubitarunt etymologiae subicere omnem nominis causam, ut ex habitu, quem ad modum dixi, "Longos" et "Rufos", ex sono "stertere" "murmurare", etiam derivata, ut a "velocitate" dicitur "velox", et composita pleraque his similia(...)

Algunos no dudaron referir todas las causas de las palabras a la etimología, así, por su apariencia, como antes indiqué, "Longo" (largo) y "Rufo" (rojizo), por su sonido, "roncar" y "murmurar", e igualmente las derivadas, como "velox" se dice de "velocitate", y la mayor parte de los compuestos semejantes a estos.

De acuerdo con la cita de Quintiliano, velox se dice que es una palabra derivada de velocitate. Salta a la vista que el orden de los factores no parece familiar, ya que, más bien, se diría que velocitate es palabra derivada de velox, la cual representa la forma para el nominativo singular.

Aunque no se encuentran testimonios escritos del empleo de este verbo en oraciones transitivas, en cuanto verbo transitivo, derivare exige la presencia de un complemento directo. La 
información suministrada por Quintiliano nos permite asegurar que en una oración de este tipo el sujeto, es decir, el elemento que produce la desviación, que desvía a una palabra, es la palabra que hoy llamaríamos derivada, lo cual es consistente con la etimología de la palabra. Así, por ejemplo, en latín se escribiría patronus derivat patrem, es decir, literalmente la voz patronus ha modificado, alterado, a pater, por lo que la voz derivada vendría a ser pater, no patronus.

Para los hablantes del español este sentido puede parecer un poco extraño, ya que se está más familiarizado con construcciones como: tal palabra deriva de tal otra, en la que se registra un uso intransitivo del verbo. Sin embargo, también puede usarse derivemos la palabra amor, para expresar el sentido de obtener las voces derivadas de amor, usos registrados por el Diccionario Panhispánico de Dudas, que al respecto consigna:

derivar(se). Con el sentido de 'provenir', es intransitivo (pronominal o no) y lleva un complemento de origen con de: «El aumento de contraste no deriva de un refuerzo de colores» (Costa Fotografía [Chile 1993]); «Esta amenaza se deriva de varios factores» (País [Esp.] 25.9.96). Cuando significa 'encaminarse a otro lugar, desviándose del rumbo original', es intransitivo no pronominal y lleva un complemento de destino con hacia $\mathrm{o}$, menos frecuentemente, $a$ : «La conversación derivó hacia temas menos dramáticos» (Savater Caronte [Esp. 1981]). De este sentido deriva el actual de 'desembocar o transformarse una cosa en otra distinta', caso en el que el complemento va introducido por en: «La desazón derivaba en languidez» (Longares Romanticismo [Esp. 2001]). Como transitivo, con el sentido causativo de 'hacer que [algo o alguien] tome un rumbo determinado, desviándose del original', el complemento directo suele ir acompañado de un complemento con hacia o a: «Como el director estaba ocupado, los derivaron a mi despacho» (Verbitsky Vuelo [Arg. 1995]) (2005: 215).

No sería admisible, por agramatical, la expresión: esta palabra deriva tal otra, mas sí esta palabra derivó en tal otra.

La corrección de patronus derivat patrem se colige de numerosas referencias gramaticales en escritores romanos, quienes, si bien es cierto no la emplean en su sentido activo, mencionan algunos de los participios pasados del verbo, a saber, derivatus y derivativus, ambos con el mismo significado.

En sus Institutiones, Prisciano atestigua el empleo de la voz pasiva de este verbo:

nec solum in pronominibus deriuatiuis, sed etiam in nominibus possessiuis et quae a propriis deriuantur, infinitae possunt intellegi possessiones, nisi adiectione nominis alicuius discernantur, ut meus filius, Telamonius natus, Euandrius ensis, et uide, quod appellatiua magis asciscunt, quae communis sunt qualitatis (CGL 2, 588).

No solo en los pronombres derivados, sino también en los posesivos y los que se derivan de los propios, puede entenderse una posesión indeterminada, a menos que sean delimitados por la adjunción de algún sustantivo, como meus filius (mi hijo), Telamonius natus (el hijo de Telamonio), Evandrio ensis (la espada Evandria), y mira que los apelativos admiten todavía más, pues son de cualidad común.

En la expresión quae a propriis deriuantur se aprecia que ha operado un cambio de régimen verbal. Nótese que Prisciano se refiere a los nomina possessiua que derivan de los nomina propria. Salta a la vista que aquí sigue el orden lógico que nos resulta afín, ya que en los tiempos cercanos a Augusto la construcción habría sido inversa.

A partir de esta época, tal uso prevalecerá. Así lo atestigua posteriormente el Digesto de Justiniano:

Hi "magistri" appellantur. Quin etiam ipsi magistratus per derivationem a magistris cognominantur (Dig. 50.16.57, 2005: 12).

A estos se les llama "maestros". Los mismos magistrados son llamados de esta manera por derivación de la palabra "maestros".

Nótese el complemento preposicional a magistris.

Unos cien años después, en el capítulo I de sus Etymologiarum, dedicado a la grammatica, Isidoro de Sevilla atestigua el siguiente uso:

Derivativa eo, quod es alio nomine deducantur, ut a monte "montanus".

Derivados son, en cambio, los que proceden de otra palabra, como "montano" de monte (2009: 282, I.8) 
El cambio semántico y sintáctico se ha consolidado y, a estas alturas, es irreversible.

\section{Del sufijo-arius, -aria,-arium}

Corresponde ahora examinar los aportes del latín al español a través del sufijo -arius, -aria,-arium, que derivó al español en -ario, -aria.

De acuerdo con la Real Academia de la Lengua Española

-ario, ria. (Del lat. -arǐus). suf. Forma adjetivos que indican relación con la base derivativa. Bancario, embrionario. \|2. Forma sustantivos que significan, entre otras cosas, profesión. Boticario, ferroviario. $\|$ 3. Se refiere a la persona a quien se cede algo. Concesionario. $\|$ 4. Señala el lugar donde se guarda lo significado por el primitivo. Campanario, relicario (2001: 203).

En latín este sufijo es propio y característico de la derivación nominal,

servía para formar adjetivos y sustantivos; las inscripciones nos han conservado una serie de nombres de profesiones en -arius (por ejemplo, saccarius, "fabricante de sacos"; burgarius, "soldado que sirve en un burgus"; centenarius, "especie de centurión" -neologismo por centurio-, pecuarius, "criador de ganado bovino", etc.) y hay nombres de utensilios, de recipientes en -arium (y, con mucha menos frecuencia, en -arius), como, por ejemplo, atramentarium, "tintero", panarium "artesa"; pultarius "puchero", etc. Es posible que muchas de estas formaciones no fueran formaciones tardías y vulgares: se trata en gran parte de palabras con un sentido muy especial que podían existir muy bien en época clásica e incluso ser usadas, llegado el caso, en la lengua hablada de gentes cultivadas, sin, pese a ello, haberse conservado en los textos literarios (Herman, 2001: 126).

La aparición de este sufijo data del período arcaico de la literatura latina, cuando los autores latinos lo emplearon en la elaboración de elementos paratextuales como los títulos de sus comedias. La influencia tiene su origen en Gneo Nevio quien introdujo ciertas modificaciones lingüísticas al momento de titular sus obras, así tenemos Carbonaria, La carbonera; Chlamydaria, La comedia de la clámide; Corollaria, La comedia de la de la coronita;
Nervolaria, La comedia de la flaquita; Testicularia, La comedia de los testículos; Tunicularia, La comedia de la faldita ${ }^{1}$. Este recurso fue heredado por Plauto, el que a su vez generó términos como Aulularia, La comedia de la ollita; Cistellaria, La comedia de la cesta; Vidularia, La comedia del baúl; Mostellaria, La comedia del fantasma; y Asinaria, La comedia del asno.

Estos sufijos también se emplearon en la atellana, en la que Novio presenta obras como Gallinaria, La comedia de la gallina; Lignaria, La comedia del leño; Tabellaria, La comedia de la tabla; y Togularia, La comedia de la toguita, junto a la Sarcularia, La comedia de la escardadora; de Pomponio y la Aulularia, La comedia de la ollita; de Laberio, esta última en el mimo ${ }^{2}$.

En la comedia togata Afranio tiene un Temerarius, El temerario, y un Cinerarius, El peluquero. Paralelo a este proceso, Afranio realizó una modificación distinta mediante patella, plato, y creó un adjetivo Patellea para La comedia del plato ${ }^{3}$.

Víctor José Herrero indica que se trata de un sufijo sustantival y adjetival, en ambos casos, con $\bar{a}$. Entre los ejemplos que él ofrece para el primer grupo están sicārius, sicario, sextārius, sextario, $6^{\text {a }}$ parte del congio, datārius, regalo, viridārium, jardinero; mientras que para el segundo, nefārius, abominable, contrārius, contrario, vicārius, representante, temerārius, casual, gregārius, del rebaño, de la masa (1971: 148-150).

Sobre el tema, Veikko Väänänem señala con gran profundidad que existen

Adjetivos a partir de nombres de objetos: urceus aquarius "cántaro", asinus molarius "asno que hace girar la muela", etc.; ha hecho concurrencia a -aris, -are: App. Pr. 69 "primipilaris, non primipilarius", Val. Max. 6, 1, 12 manipularius miles=manipularis m. (Baehrens, pág. 121); sustantivos para designar a profesionales que producen, fabrican, trabajan, venden tal o cual género, en concurrencia con -tor, -trix, proliferan en latín popular y técnico y en las lenguas románicas (rum. -ar, it. -aio y -aro, fr. -ier, esp. -ero, port. eiro, cat. -er), por ej. operarius "obrero", librarius "copista", lignarius "leñador", saccarius "descargador" y "fabricante de sacos", veterarius 
"remendón", taurarius "torero" (Pompeya, hapax), cubicularius, -is "ayuda de cámara", "criada", ostiarius, -ia "portero, portera" (1967: 142, 175).

Respecto de la formación de sustantivos, Väänänem indica:

-aria. Nombres de oficio o de comercio obtenidos por elipsis de grupos, como taberna o ars argentaria, etc., y usados sobre todo como complementos de objeto de facere "ejercer": argentaria "banco", saccaria "oficio de descargados" (Apul.), salsamentaria "salchichería" (Pompeya, hapax), scrutaria "baratillo" (glos.) unguentaria "perfumería"; uso especial: nombres de comedias de Plauto Asinaria o "Fábula de los asnos", Aulularia o "Fábula de la marmita", Cistellaria o "Fábula de la caja", Mostellaria o "Fábula de las rentas". En romance, este sufijo designa más en especial una cantidad de algo determinado o el lugar donde se encuentra en gran cantidad (cf. K. Baldinger, Kollektivsuffixe una Kollectivbegriffe, Berlín, 1950, pág. 236 ss.) (1967: 143, 177).

Otro grupo de palabras proceden del sufijo -ārium, en particular

Nombre de recipientes o de espacios donde se conserva tal o cual cosa, y sus congéneres: aerarium "hacienda pública", atramentarium "tintero", granarium "granero", panarium "artesa", tabularium "archivo", solarium "terraza de sol” (a. fr. solier), virid(i)arium $>$ fr. verger, etc.; sentido especial: "suma de dinero entregada para tal gasto", por ej. calcearium (para calzado), exsequiarium (para las exequias), salarium (para sal, como consecuencia "salario"), vestiarium (para vestidos; otro sentido: “armario", "guardarropa”) (1967: 142-143, 176).

Fácilmente nos viene a la mente la voz notario en español, que deriva de notarius, sobre ella san Isidoro de Sevilla apunta esta explicación:

De notis uulgaribus

1. Vulgares notas Ennius primus mille et centum invenit. Notarum usus erat ut, quidquid pro con[ten] tione aut [in] iudiciis diceretur, librarii scriberent conplures simul astantes, divisis inter se partibus, quot quisquie verba et quo ordine exciperet. Romas primus Tullius Tiro Ciceronis libertus commentus est notas, sed tantum praepositionum. 2. Post eum Vipsanius, Philargius, et Aquila libertus Maecenatis alius alias addiderunt. Deiden Seneca, contractu omnium digestoque et aucto numero, opus efficit in quinque millia. Notae autem dictae eo, quod verba vel syllabas praefixis characteribus notent et ad notitiam legentium revocent; quas qui didicerunt proprie iam notarii appellantur (2009: I. 22.1-2.).

Primero Ennio inventó mil cien abreviaturas vulgares. El uso de las abreviaturas consistía en que cualquier cosa que se dijera ante la asamblea $\mathrm{o}$ en los juicios, varios amanuenses presentes las escribirían simultáneamente, distribuyéndose las partes entre sí y cuántas palabras, así como en qué orden cada uno las captaría. En Roma, primero Tulio Tirón, liberto de Cicerón, comentó sobre las notas, pero solo de las preposiciones. 2. Después de él, Vipsanio, Filargio y Aquila, liberto de Mecenas, cada uno de ellos añadió otras. Después Séneca, reunidas y clasificadas, así como aumentadas en número, hizo una obra con cinco mil. Se llaman "notas" pues denotan palabras o sílabas mediante símbolos predefinidos y las conservan para inteligencia de los lectores. Quienes las han aprendido con propiedad son llamados "notarios".

\section{Conclusiones}

Este breve trabajo ha mostrado, por un lado, cómo ciertos procesos evolutivos de la lengua latina continúan presentándose en el uso contemporáneo del español. El fenómeno no es extraño, por cuanto rara vez responden exclusivamente a determinadas características de una lengua específica. Responden, en cambio, a leyes fonéticas o lingüísticas muy conocidas.

Por otra parte, se ha podido establecer una raigambre sumamente antigua en las voces terminadas en -aria, la cual se remota no solo a la Roma arcaica, sino a una parte de su literatura, la que no has llegado a través de los siglos.

\section{Notas}

1. von Albrecht, Michael, (1997), p. 134

2. Ballester, Xaverio, (1998), p. 38.

3. Ribbech, citado por Lóprez López, Aurora, (1983), p. 253. A esta comedia togata, para Ritschl, posiblemente habría que sumar una Vaccaria o Baccaria. Véase Ballester, Xaverio, (1998), p. 38. 


\section{Bibliografía}

Ballester, Xaverio. (1998). Los mejores titulos y los peores versos de la literatura latina, $1^{\text {a }}$ edición, Publicaciones de la Universitat de Barcelona, Barcelona.

Cicerón. De finibus bonorum malorumque, II, 78. consultado el 23 de octubre del 2012 en https://www.thelatinlibrary.com/ cicero/fin2.shtml\#78.

Oxford. (2007). Oxford Latin Dictionary. Edited by P. G. W. Glare. Reprinted. Oxford University Press Inc. New York.

Herman, Jósef. (2001). El latín vulgar. Edición española reelaborada y ampliada con la colaboración de Carmen Arias Abellán. $1^{a}$ reimpresión. Editorial Ariel, S. A. Barcelona.

Herrero Llorente, Víctor-José. (1971). La lengua latina en su aspecto prosódico, con vocabulario de términos métricos. Editorial Gredos, S. A. Madrid, España.

Isidoro de Sevilla. (2009). Etimologías. Edición bilingüe. $2^{\mathrm{a}}$ reimpresión. Biblioteca de Autores Cristianos. Madrid.

Justiniano. (2005). Sobre el significado de las palabras (Digesto 50.16). Versión de Martha Patricia Irigoyen Troconis. $2^{\mathrm{a}}$ edición, corregida y aumentada.

Lewis, Charlton T. (1879). A Latin Dictionary Founded of Andrew's Edition of Freund's Latin Dictionary Revised, Enlarged, and in Great Part Rewritten. $1^{\text {st }}$ Edition. Oxford University Press Inc. New York.
López López, Aurora. (1983). Fabularum togatarum fragmenta, $1^{\text {a. }}$ edición, Ediciones Universidad de Salamanca, Salamanca.

Real Academia de la Lengua Española. (1992). Diccionario de la lengua española. a-g. Tomo I. 21 a edición. Editorial Espasa Calpe, S. A. Madrid.

Real Academia de la Lengua Española. (2012). Diccionario de la lengua española. a-g. Tomo I. 22a edición. consultado el 24 de octubre del 2012 en http://lema.rae.es/ drae/?val=derivar

Real Academia de la Lengua Española. (2001). Diccionario de la lengua española. a-g. Tomo I. 22 ${ }^{\mathrm{a}}$ edición. Editorial Espasa Calpe, S. A. Madrid.

Real Academia de la Lengua Española. (2005). Diccionario panhispánico de dudas. Santillana Ediciones Generales, S. L. Madrid.

Segura Munguía, Santiago. (2003). Nuevo diccionario etimológico Latín-Español y de las voces derivadas. $1^{\mathrm{a}}$ reimpresión. Universidad de Deusto. Bilbao.

Priscianus. (). Prisciani Institutiones.

Väänānem, Veikko. (1967). Introducción al latín vulgar. Editorial Gredos, S. A. Madrid.

Von Albrecht, Michael. (1997). Historia de la literatura romana, desde Andrónico hasta Boecio. Volumen I, 1a. edición, Empresa Editorial Herder, S. A., Barcelona.

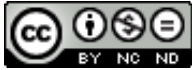

Este obra está bajo una licencia de Creative Commons

Reconocimiento-NoComercial-SinObraDerivada 4.0 Internacional. 
